\title{
Glycyrrhiza glabra L. Bitkisinin Türkiye'de Yetişmekte Olan Varyetelerinin Farmakognozik Karşılaştırılması*
}

\author{
Pharmacognostical Comparison of the Varieties of Glycyrrhiza \\ glabra L., Growing in Turkey \\ Mekin TANKER** \\ Nazire ÖZKAL**
}

Glycyrrhiza glabra L. çok eski zamanlardan beri gerek halk arasında ve gerekse tıbbi tedavi alanında çok kullanılan bir bitkidir. Halen antispazmotik, antienflamatuar ve antiasit etkilerinden yararlanılarak ülsere ve üst solunum yolları hastalıklarına karşı kullanılan preparatların bileşimine giren saponozit (glisirizik asit) ve flavonozitleri (likiritozit ve izolikiritozit) içeren bu drog memleketimiz ekonomisi yönünden de değerli bir ihraç maddesidir (1).

Bugüne kadar G. glabra'nın tesbit edilmiş 5 varyetesi bulunduğu halde, R. Liquiritiae ile ilgili araştırmalar sadece içerdiği etken maddelerin saptanması ve bu maddelerin farmakolojik etkileri üzerinde yapılmıştır. Ancak varyeteler arasında etkinlik yönünden bir farklılık bulunup bulunmadığı incelenmemiştir.

Dolayısıyle değerli bir drog olan G. glabra'nın bütün varyetelerinin aynı amaçlarla kullanılıp kullanılamıyacağını ya da etkinlik yönünden hangisinin diğerlerine tercih edilmesi gerektiğini araştırmayı düşündük.

Araştırmalarımızın birinci kısmıni oluşturan botanik incelemelerimizde $G$. glabra bitkisini 4 varyete altında toplamıştık (1). Çalış-

Redaksiyona verildiği tarih: 24 Mart 1978.

* Ecz. Nazire Özkal'm aym isimli Doktora Tezinin Kimyasal kismenn özetidir (Sinav tarihi : Haziran 1977). Ilk kısım bu derginin 1977/2 sayısında yayınlanmıștır. Üniversitesi.

** Farmakognozi ye Farmasötik Botanik Kürsüsü, Eczacılık Fakültesi, Ankara 
malarımızın devamını oluşturan kimyasal incelemelerimizle de bu varyeteler arasındaki farklar farmakognozi açısından değerlendirilmiştir.

\section{MATERYEL ve YÖNTEM}

Ưzerinde çalıştı̆ımız kök ve rizomlar 1973-75-76 senelerinin mayıs ayı sonları, haziran ve temmuz aylarında Doğu, Güneydoğu, Güney Anadolu'nun çeşitli yörelerinden topladığımız G. glabra varyetelerinden elde edilmiştir.

Genellikle yol kenarlarındaki tarlalarda, yamaç, nehir ya da dere yataklarındaki kumluk arazide bulunan bitkilerin kök ve rizomları, 0.5-1 m kadar kazılarak toprak altından çıkarılmıştır.

Kimyasal incelemeler için kullanılan ve 4 grup altında toplayabildiğimiz örnekler 12 ayrı yerden toplanmıştır.

A- Glycyrrhiza glabra var. glandulifera form. (a).

1- Varto (Muş): $1700 \mathrm{~m}$

2- Alpaslan D.Ù.Ç . civarı (Muş): $1500 \mathrm{~m}$

3- Aksu (Antalya): $15 \mathrm{~m}$

B- Glycyrrhiza glabra var. glandulifera form. (b)

1- Diyarbakır, Dicle nehri civarı: $660 \mathrm{~m}$

2- Akziyaret (Urfa): $560 \mathrm{~m}$

3- Belen yaylası (Hatay): $600 \mathrm{~m}$.

C- Glcyrrhiza glabra var. glabra

1- Bulanık yol ayırımı (Muş): $1700 \mathrm{~m}$

2- Tatvan-Güroymak arası: $1500 \mathrm{~m}$

3- Muş ovası: $1500 \mathrm{~m}$

4- Tercan (Erzincan): $1390 \mathrm{~m}$.

D- Glycyrrhiza glabra var, violacea

1- Aligör-Suruç yol ayırımı (Urfa): $560 \mathrm{~m}$

2- Maraş-Göksun yol kenarları: $700 \mathrm{~m}$ 
Kimyasal incelemeler için ayrılan kök ve rizomlar, toprak üstü kısımlarından kurtarılarak gölgede, 3-4 ay kurutulmuş ve öğutücüde toz edilmiştir.

Araştırmalara Farmakopelerin önerdiği genel miktar tayinleri ile başlanmıştır.

Materyelimizin saponozit içerdiği renk reaksiyonları ile saptandığından köpürme indeksi tayin edilerek, hemoliz özeliği incelenmiştir.

Ayrıca saponozitin varlığı içerdiği glisirizik asitin aglikonu olan $18 \beta$-glisiretik asitin ince tabaka kromatografisinde verdiği leke ile de saptanmıştır.

Glisirizik asitin miktarı, aglikonun yani $18 \beta$-glisiretik asitin vanilin $-\mathrm{H}_{2} \mathrm{SO}_{4}$ ile renklendirilerek $\lambda_{\max }=545 \mathrm{~nm}$ deki ekstinksiyon değerinin ölçülmesi ile spektrofotometrik olarak yapılmıştır.

Flavonozit kontrolu için kök ve rizomlar Soxhlet apareyinde bir düze organik solvanla tüketilmiştir. Elde edilen ekstreler ince tabaka kromatografisine uygulanmıştır. Ayrıca metanollü ekstrenin pozitif siyanidin reaksiyonu vermesinden ve diğer renk reaksiyonlarından flavonozit varlı̆̆ı saptanmıştır.

Flavonozitlerin miktar tayinleri ise hidrolizleriyle ayrilan flavonoitlerinin (flavanon ve kalkon) spektrofotometrede ölçülen ekstinksiyon değerlerinden yararlanılarak yapılmıştır.

\section{BULGULAR}

Örnek tozları üzerindeki incelemelerimiz 2 grup altında toplanabilir:

1- Farmakopelerce aranan genel miktar tayinleri

1.1. Kuruma kaybı; USP XVII'de belirtilen gravimetrik yönteme göre $105^{\circ} \mathrm{C}$ lik etüvde kurutularak saptanan değerler Tablo I'de gösterilmiştir.

1.2. Käl miktarı; $800^{\circ} \mathrm{G}$ lik firın kullanılarak tayin edilmiş (Ph.Fr.IX) ve \% miktarları hesaplanmıştur (Tab. 1).

1.3. Asitte erimeyen kül miktarı; total külün asit ile kaynatıldıktan sonra yakılmasıyla hesaplanmıs ve Tab. 1 de verilmiştir. 
1.4. Su ile tüketilebilen madde miktarı; toz numunenin su ile masere edilmesi sonucu (Ph.Fr.IX) hesaplanmıs ve \% $14-28$ arasında değerler bulunmuştur (Tab. 1).

2- Etken madde tanımı ve miktar tayini

\subsection{Saponozit:}

\subsubsection{Saponozitin (Glisirizik asit $=$ Glisirizin) tanın-} masi.

2.1,11 . Renk reaksiyonlar1: Toz numunenin veya metanollü ekstresinin vermiş olduğu renk reaksiyonları ile saponozitin varlığı saptanmisttır.

a) Salkowski reaksiyonu ile sarı renk,

b) Liebermann-Burchard reaksiyonu ile önce kırmızı sonra sarı-kahverengi bir renk,

c) Yoğunlaştırılmış metanollü ekstrenin anisaldehit-sülfürik asit reaktifi ile önce pembe, sonra mor bir renk vermesi saponozitin triterpenik yapıda olduğunu gösterir.

2.1.12. Köpüirme indeksi: Kök ve rizomların sulu ekstresi çalkalandığında da kalıcı bir köpük meydana gelir.

Köpürme indeksi, ancak \% 1 lik dekoksiyondan hazırlanan gam ile saptanabilmiştir (Tab. 1).

2.1.13. Hemoliz özeliği: Droğun sulu çözeltisi emdirilmiş süzgeç kâğıdı eritrosit çözeltisine batırıldığında hemoliz özeliği görülmemektedir.

2.1 14. Ince tabaka kromatografisi: Ayrıca droğun içerdiği saponozitin aglikonu yani $18 \beta$-glisiretik asit te ince tabaka kromatografisi ile saptanmıştır. Toz drog $\mathrm{IN}-\mathrm{H}_{2} \mathrm{SO}_{4}$ ile 5 saat kaynatılarak hidroliz edilmiştir. Kloroformla tüketilen hidroliz ürünü "silicagel $\mathrm{GF}_{254}$ Merck" ile kaplanmıs plaklara uygulanarak kloroform: metanol (95:5) solvan sistemi ile develope edildiğinde $\mathrm{Rf}$ değeri $(0.3)$ ve görünümü bakımından (anisaldehit püskürtüldüğünde mavi-mor renkli) saf madde ile eş olan bir leke görülmektedir. Bu da aglikonun $18 \beta$-glisiretik asit olduğunu kanıtlamıştır (Ph. Fr. IX).

2.1.2. Saponozitin (Glisirizik asit) miktar tayini: Toz edilmiş kök ve rizom örnekleri $\mathrm{IN}-\mathrm{H}_{2} \mathrm{SO}_{4}$ ile hidroliz edilmiştir (Ph, Fr. IX). Ancak hidrolizin tam olabilmesi için 5 saat süre ile kay- 
Tablo I. Glycyrrhiza glabra varyetelerinin toprakaltı kısımlarınm nicel özelikleri

\begin{tabular}{|c|c|c|c|c|c|}
\hline G. glabra varyeteleri & Kuruma kaybı & Kül \% & $\begin{array}{c}\text { Asitte erimeyen } \\
\text { Kül \% }\end{array}$ & $\begin{array}{c}\text { Su ile tüketilebi- } \\
\text { len Madd. } \%\end{array}$ & $\begin{array}{c}\text { Köpürme } \\
\text { Indeksi }\end{array}$ \\
\hline var. glanciaitiera forma (a) & $4.69-6.83$ & $3.81-5.49$ & $0.41-0.60$ & $20.76-28.01$ & 250 \\
\hline var. glandulifera form (b) & $5.36-5.98$ & $4.58-6.54$ & $0.69-1.25$ & $16.80-21.30$ & 200 \\
\hline var. glabra & $5.45-6.98$ & $3.98-6.93$ & $0.74-1.85$ & $22.75-25.17$ & 250 \\
\hline var. violacea & $4.79-5.62$ & $5.25-6.77$ & $0.63-1.00$ & $14.19-15.55$ & 166.6 \\
\hline
\end{tabular}


natmak gerekmektedir. Soğutulduktan sonra kloroform ile tüketilmiştir. $\mathrm{Bu}$ işlem aglikonun tamamı alınıncaya kadar birçok kereler tekrarlanmiştır. Kloroformlu fazlar birleştirilerek susuz sodyum sülfat ile kurutulup $100 \mathrm{ml}$ ye tamamlanmıştır. Bu çözeltinin $1 \mathrm{ml}$. si fosfat tamponu ile tamponlanmış "silicagel $0.05-0.20 \mathrm{~mm}$ Merck" ve aktif kömür karışımı ile hazırlanmış çapı $1 \mathrm{~cm}$, boyu $40 \mathrm{~cm}$ olan kolondan, yine tamponlanmış kloroform çözeltisi ile elüe edilmiştir. Toplanan $20 \mathrm{ml}$ çözelti uçurulduktan sonra, önce \% 80 lik $\mathrm{H}_{2} \mathrm{SO}_{4}$ ile asitlendirilip daha sonra vanilin reaktifi ile renklendirilerek UV spektrofotometresinde $\lambda_{\max }=545 \mathrm{~nm}$ deki ekstinksiyon değeri ölçülmüş̧ür.

Aynı şartlarda standart olarak kullanılan $18 \beta$-glisiretik asitin de ekstinksiyon değeri ölçülerek şu formüle göre örneklerimizin içerdiği glisirizik asitin \% miktarları hesaplanmıştir (DAB 7-DDR).

$\%$ glisirizik asit $=\frac{\mathrm{E}_{1} \times 437}{\mathrm{E}_{2} \times \mathrm{E}_{\mathrm{w}}(100-\mathrm{a})}$

$\mathrm{E}_{1}=$ örnek çözeltisinin ekstinksiyon değeri

$\mathrm{E}_{2}=$ standart çözeltisinin ekstinksiyon değeri

$\mathrm{E}_{\mathrm{w}}=$ örnek miktarı

$\mathrm{a} \quad=$ numunenin kuruma kaybı yüzdesi

Saptanan sonuçlar Tab. II de gösterilmiştir.

Değişik yörelerden toplanan örneklerdeki glisirizik asit miktarı, varyetelerle olduğu gibi yetiştikleri yerle de ilgili olarak değişme göstermektedir. Şöyle ki, glisirizik asit miktarı, 1300-1700 m yükseklikte yetişen bitkilerde daha fazladır (Varto \% 11.2; Bulanık \% 12.5). Ayrica Akdeniz iklimine sahip yörelerden toplanan örnekler de etken madde miktarı yönünden yüksek yerlerde yetişenlere daha yakındır (Belen \% 9.5; Aksu \% 9-9.5).

\section{2 . Flavonozit}

2 .2 .1 Flavonoitlerin tanınması: Örneklerin içerdiğiflavonozitler de renk reaksiyonları ve ince tabaka kromatografisi ile tanınmıştır. 
2.2.11. Renk reaksiyonları: Metanollü ekstrelere uygulanmiştır:

a) Seyreltik sodyum hidroksit çözeltisi ile sarı bir renk,

b) Derişik antimon triklorür çözeltisiyle sarı bir çökelek,

c) \% 5 lik ferri klorür çözeltisiyle de siyahımsı-yeşil bir renk ve çökelek oluşmaktadır.

2.2.12. Siyanidin reaksiyonu; ile oluşan menekşe renk te örneklerimizin flavanon türevi maddeler içerdiğini göstermiştir.

2.2.13. Ince tabaka kromatografisi: Meyan kökü örneklerinin, Soxhlet apareyinde sirasiyla eter, etilasetat, metanol ile tüketilmesiyle elde edilen ekstreler, "kieselgel G" ile kaplanmış plaklara (2) uygulanmıs ve etilasetat: metanol: su (100:17:13) solvan sistemi ile develope edilmiştir. Kalkona (izolitiritigenol) ait lekeler gün ı̧̧ığında sarı, UV/366 da koyu kahverengi, $\mathrm{AlCl}_{3}$ püskürtüldükten sonra UV/366 da yine sarı renkte görülür. Gün ısı̆ğında görülemeyen flavanon (likiritigenol) lekeleri ise UV/366 da mavi ve yeşil floresans gösterirler. $\mathrm{AlCl}_{3}$ ile işlemden sonra bu lekeler daha da parlaklaşır.

2.2.21. Kalkon (izolikiritigeno1) miktar tayini: Meyan kökü tozu IN- $\mathrm{H}_{2} \mathrm{SO}_{4}$ ile hidroliz edildikten sonra kloroformla tüketilmiştir. Kloroforma alınan aglikonun UV spektrofotometresinde $\lambda_{\max }=496 \mathrm{~nm}$ deki ekstinksiyon değeri ölçülür. Tanık çözeltinin değişik dilüsyonlarının da aynı dalga boyunda ölçülen ekstinksiyon değerlerine göre çizilen kalibrasyon eğrisi yardımıyla kalkon miktarı hesaplanmıştır (Tab. II).

2.2 .22 , Flavanon (likiritigenol) miktar tayini: Yine UV spektrofotometresinde okunan ekstinksiyon değerlerine göre hesaplanmıstır. Glisiretik asit ve kalkon miktar tayinlerinde kullanılmak üzere kloroformla tüketilmiş olan hidroliz ürünü eterle ekstre edilmiş ve eter uçurulmuştur. Artık metanolde çözülmüş ve asitlendirildikten sonra $\mathrm{Mg}$ tozu ilâve edilmiştir (siyanidin reaksiyonu). Oluşan menekşe rengin $\lambda_{\max }=550 \mathrm{~nm}$ deki ekstinksiyonu ölçülmüştür. Tanık olarak kullanılan naringetol'ün değişik konsantrasyonlarının aynı şartlarda ölçülen ekstinksiyonuna göre çizilen kalibrasyon eğrisinden de miktar tayinine geçilmiştir (Tab. II). 
Tablo II. Glycyrrhiza glabra varyetelerindeki etken madde miktarları

\begin{tabular}{|l|c|c|c|}
\hline \multicolumn{1}{|c|}{ G. glabra varyeteleri } & Glisirizik asit \% & Kalkon \% & Flavanon \% \\
\hline var. glandulifera form (a) & $9.03-11.22$ & $0.84-1.48$ & $1.1-2.45$ \\
var. glandulifera form (b) & $6.3-9.5$ & $0.61-1.54$ & $1.75-2.1$ \\
var. glabra & $8.0-12.5$ & $0.84-1.38$ & $0.95-2.15$ \\
var, violacea & $4.4-4.6$ & $0.69-1.14$ & $1.55-1.85$ \\
\hline
\end{tabular}

\section{TARTISSMA ve SONUC}

Bu dört varyete üzerinde yapılan kimyasal incelemeler sonunda; glisirizik asidin G. glabra var. glandulifera form. (a) da \% 9-11, G. glabra var. glabra da \% 8-12.5 miktarında bulunuşu dikkati çekmektedir. Buna karşılık $G$, glabra var. violacea'nın toprak altı örneklerinde glisirizik asit miktarının \% 4.5 gibi oldukça düşük miktarda olduğu saptanmaktadir. G. glabra var, glandulifera form (b) nin toprak altı numunelerinde $\%$ 6.5-9.5 değerleri ile nisbeten düşük miktarda glisirizik asit taşıdığı görülmektedir. Ancak bu varyeteye iklimin etkisinin olduğu, Akdeniz iklimi görülen yörelerden alınan örneklerde söz konusu asit miktarının (Belen'den alınan numunede) \% 9.5 olarak saptanması ile kanıtlanmaktadır.

$\mathrm{Bu}$ bitkiden elde edilen droğun etkin maddelerinden bir bölümünün de flavonoid bileşikleri olduğu bilinmektedir. Ayrı varyetelere ait toprak altı numunelerinde flavanon (likiritigenol) yönünden yapılan kimyasal incelemeler sonuçlan da varyetelere göre ayrıcalık göstermektedir. Bu grup bileşiklerin spektrofotometrik miktar tayinleri sonucunda G. glabra var. glandulifera form. (a) için $\%$ 1.1-2.45, G. glabra var. glandulifera form. (b) için \% 1.75-2.10, G, glabra var. glabra için \% $0.95-2.15$ ve G.glabra var. violacea içinse $\%$ 1.55-1.85 değerleri saptanmıştır. Kalkon miktarları ise aynı sira ile $\% 0.84-1.48,0.61-1.54,0.84-1.38$ ve $0.69-1.14$ değerlerindedir. Burada açıkça görüldüğü gibiflavonoid miktarının da en düşük olduğu varyete yine $G$. glabra var. violacea'dır.

Böylece kimyasal çalı̧̧malar sonunda elde edilen verilere dayanilarak G. glabra L. bitkisinin varyetelerinden $G$. glabra var. glandulifera form. (a) ve G. glabra var. glabra'nın ve kismen de $G$. glabra var. glandulifera form. (b) nin özellikle Akdeniz iklimi görülen yörelerden 
toplanan toprakaltı kısımlarından, daha yüksek kalitede offisinal drog elde edilmesinin uygun olacağı sonucuna varılmışur.

Ayrica 1974 Türk Farmakopesi'nde yer almiyan fakat geniş bir kullanima alanına ve ekonomik değere sahip olan bu droğun tekrar farmakopeye alınmasının yararlı olacağı kanısındayız. Bu nedenle T.F. si için bir de monografi önerilmiştir (3).

\section{ÖZET}

Bu çalışmada Anadolu'nun birçok bölgesinde yaygın olarak bulunan Glycyrrhiza glabra L. (meyan) bitkisinin 4 varyetesine ait ve değişik yörelerden toplanan örnekler kullamılmıştır.

Bu varyetelerin kurutulup, toz edilmiş toprak altı kısımlarında farmakopelerce istenen genel miktar tayinleri yapılmış ve varyeteler için şu değerler saptanmiştır. Kuruma kaybı: \% 4 .79-6.98, kül miktarı: \% 3.81-6.93, asitte erimeyen kül miktarı: \% $0.41-1,00$, su ile tüketilebilen madde miktarı ise \% 14.19-28.01. Köpürme indeksi ise var. glandulifera form (a) ve var. glabra için 250, var. glandulifera form (b) için 200 ve var. violacea için de 166.6 olarak bulunmuştur.

Örneklerdeki glisirizik asit miktarı, toz numuneden asit hidroliziyle ayrılan $18 \beta$-glisiretik asitin vanilin- $\mathrm{H}_{2} \mathrm{SO}_{4}$ reaktifi ile verdiği rengin $\lambda_{\max }=545 \mathrm{~nm}$ deki ekstinksiyon değerinin ölçülmesiyle spektrofotometrik olarak hesaplanmış ve şu değerler bulunmuştur: G. glabra var. glandulifera form. (a) da \% 9.03-11.22, G. glabra var. glandulifera form. (b) de \% 6.3-9.5, G. glabra var. glabra'da \% 8.0 12.5, G. glabra var. violacea'da ise \% 4.4-4.6.

Flavonozitlerin miktar tayinleri de, toz numunenin hidrolizinden sonra oluşan flavanon (likiritigenol) ve kalkon (izolikiritigenol) türevi aglikonların UV spektrofotometresinde ölçülen ekstinksiyon değerleri ile hesaplanmıştır.

Flavanon miktar tayininde metanollü örnek çözeltisinin siyanidin reaksiyonu ile verdiği rengin $\lambda_{\max }=550 \mathrm{~nm}$ deki ekstinksiyon değeri ölçülerek varyetelere göre şu sonuçlar alınmıştur: G. glabra var. glandulifera form (a) da $\% 1,1-2.45, G$. glabra var. glandulifera form, (b) de \% 1.75-2.1, G. glabra var, glabra da \% 0.95-2.15, G. glabra var. violacea da $\% 1.55-1.85$. 
Kalkon miktar tayininde ise metanollü çözeltinin $\lambda_{\max }=496 \mathrm{~nm}$ deki ekstinksiyon değeri ölçülmüş ve şu sonuçlar alınmıştır: G. glabra var, glandulifera form. (a) da \% $0.84-1.48$, G. glabra var. glandulifera form (b) de \% 0.61-1.54, G. glabra var, glabra'da \% 0.84 1.38, G. glabra var. violacea $\mathrm{da} \%$ 0.69-1.14.

\section{SUMMARY}

In this research, the varieties (four varieties) of Glycyrrhiza glabra $\mathrm{L}$. which are wiedly spread all over Anatolia have been studied. The samples have been collected from the different parts of Anatolia.

The classical assays which are mentioned by the pharmacopeias have been made on the powdered samples of the underground parts of these varieties. The amounts have been determined such as: loss on drying \% 4.79-6.98, total ash \% 3.81-6.93, acid insoluble ash $\% 0.41-1.00$, water-soluble extracts $\% 14.19-28.01$. The foaming index was found to be 250 for the var. glandulifera form (a) and var. glabra, 200 for the var. glandulifera form. (b) and 166.6 for the var, violacea.

The amount of glycyrrhizic acid has been determined spectrophotometrically by measuring the extinction values of the color which was formed after the reaction of $18 \beta$-glycyrrhetic acid (which was obtained as a conclusion of acid hydrolization) with vanilin $\mathrm{H}_{2} \mathrm{SO}_{4}$ at $\lambda_{\max }=545 \mathrm{~nm}$ accounted such as: $G$. glabra var. glandulifera form. (a) \% 9.03-11.2, G. glabra var, glandulifera form (b) \% $6.3-$ 9.5, G. glabra var. glabra $\%, 8,0-12.5$ and $G$. glabra var. violacea $\%$ 4.4-4.7.

The amounts of flavonoids have been also determined spectrophotometrically by measuring the extinction values of the flavanone (liquiritigenol) and the chalcone (isoliquiritigenol) derivatives which have been obtained after the acid hydrolization of the powdered samples.

The quantitative determination of flavanone derivatives has been made by measuring the extinction value of the color, which was formed by the cyanidine reaction, at $\lambda_{\max }=550 \mathrm{~nm}$, and the following values have been obtained; G. glabra var, glandulifera form (a) 
$\%$ 1.1-2.45, G. glabra var. glandulifera form (b) \% 1.75-2.10, G. glabra var. glabra \% $0.95-2.15$, G. glabra var. violacea $\% 1.55-$ 1.85 .

The amount of chalcone has been determined by measuring the extinction value of the methanollic solution at $\lambda_{\max }=496 \mathrm{~nm}$, such as: G. glabra var. glandulifera form (a) \% $0.84-1.48$, G. glabra var. glandulifera form. (b) \% 0.61-1 .54, G. glabra var. glabra \% $0.84-1.38$ and $G$. glabra var. violacea \% $0.69-1.14$.

\section{LİTERATÚR}

1. Tanker, N., Özkal, N., F. Fac. Pharm. Ankara 7, 2 (1977).

2. Stahl, E., Dünnschicht-Chromatographie, II. Auflage, Springer-Verlag, Berlin (1967).

3. Tanker, M., Özkal, N., "Glycyrrhiza glabra L. Bitkisinin Türkiye'de Yetișmekte Olan Varyetelerinin Karşılaştırılması" adlı doktora tezi (1977). 